\title{
A Expansão do Ensino Superior em Administração no Sudoeste do Paraná: Reflexões Introdutórias
}

\author{
Liliane Canopf \\ Rosane Calgaro Festinalli \\ Elisa Yoshie Ichikawa
}

\begin{abstract}
Resumo
Este artigo tem por objetivo propor um debate sobre o ensino superior, a partir da análise da expansão acelerada do número de instituições e cursos de graduação em Administração na Região Sudoeste do Paraná. Para tanto, teve como base a discussão acerca das mudanças ocorridas no papel do Estado, que culminaram na Reforma do Estado e Reforma da Educação no Brasil. A partir disso, expõe o panorama da expansão do ensino superior, com dados sobre as instituições da região como um todo e mais especificamente sobre os cursos de graduação em Administração. $\mathrm{O}$ estudo foi desenvolvido por meio de fontes secundárias, além da coleta de dados primários junto às instituições envolvidas, por meio da aplicação de um questionário. Foram pesquisadas todas as instituições de Ensino Superior da Região Sudoeste do Paraná em funcionamento no ano de 2002. Os dados mostram que nos últimos anos houve acréscimo de 300\% no número de instituições de ensino superior do Sudoeste do Estado, o que é espantoso para uma região que vem sofrendo um decréscimo paulatino de sua população nas últimas décadas. Finalmente, o artigo se propõe a refletir se, em termos qualitativos, houve ganhos no sistema educacional como um todo ou um nivelamento por baixo, por meio da efetivação da lei de mercado na educação superior.
\end{abstract}

Palavras-chave: expansão do ensino; ensino superior; graduação em Administração.

\section{Abstract}

This article intends to bring about a discussion of higher education, starting with an analysis of the fast growing number of institutions and courses offering a graduation in Administration in the Southwest Region of Paraná State. So far, it is based on a discussion and on the Reform of Education in Brazil. It points up the expansion of higher education, with data about the institutions of the region and more particularly about the graduation in Administration courses. The study was based on secondary resources, and by collecting basic data from the involved institutions, with questionnaire forms. All the institutions of higher education applying courses in the Southwest Region of Paraná in 2002 were surveyed. The information gathered showed an increase of $300 \%$ in the number of institutions of higher education in the Southwest of the State, something admirable for a region which has been having a remarkable decrease in population in the past decades. Finally, the report ponders whether, in what concerns quality, there has been advantages for the educational system as a whole or if there was a low leveling, with the sanction of the higher education market law.

Key words: educational expansion; higher education; graduation in Administration. 


\section{INTRODUÇÃO}

Diversos estudos (COVRE, 1991; LOPES, 2002; NICOLINI, 2001) descrevem o início dos cursos de ensino superior na área de Administração no Brasil por volta de 1950, a partir da demanda por profissionais capacitados, gerada pelas empresas multinacionais, escritórios de consultoria e pelo próprio governo. A expansão de empresas nacionais e multinacionais intensificou a procura por profissionais aptos para adoção da racionalidade na tomada de decisão organizacional. Os aspectos mais enfatizados na formação dos administradores eram o conhecimento e habilidades técnicas, mais apropriados para a execução das atividades impostas pelas organizações de negócios. As décadas de 1960 e 1970 presenciaram uma rápida expansão do ensino superior em Administração, incentivada pelos mesmos fatores de implantação dos cursos.

Esse processo de implantação de um grande número de novas instituições com cursos de Administração teve uma retomada no final de década de 1990. Surgem, então, questionamentos sobre as possíveis causas para a expansão. Este trabalho busca entender esse fenômeno, no caso presente, analisando a expansão dos cursos de Administração na Região Sudoeste do Paraná.

A busca para a compreensão do fenômeno aqui enfocado envolveu a realização de um estudo na seguinte sistematização: uma pesquisa bibliográfica acerca dos temas Reforma do Estado e Reforma da Educação Superior, pois se partiu da premissa de que o entendimento da rápida expansão do ensino superior na região requer a compreensão do contexto dessas reformas; coleta de dados secundários para a caracterização da Região Sudoeste do Paraná e a descrição do histórico do ensino superior até 1999 nessa região, quando ali existiam apenas três instituições de nível superior; coleta de dados primários junto a todas as instituições de ensino superior presentes na região em 2002, por ocasião da realização desta pesquisa.

Os dados mostram que nos últimos anos houve acréscimo de 300\% no número de instituições de ensino superior do Sudoeste do Estado, o que é espantoso para uma região que vem sofrendo um decréscimo paulatino de sua população nas últimas décadas. Tentar compreender esse fenômeno, portanto, é o que se irá empreender a partir deste momento. 


\section{Sobre o Papel do Estado}

Para iniciar o estudo, o presente trabalho recupera historicamente o papel do Estado. Assim, rememoramos seu papel exercido na fase histórica caracterizada por algumas medidas que visavam à unificação política de algumas nações, chamada de mercantilismo. Nesta época, o Estado exercia um papel de intervenção, aceitando as noções mercantilistas, por ver nelas uma forma de fortalecer o Estado absolutista, em face do particularismo medieval e contra os rivais estrangeiros, tendo como principais causas a queda da economia feudal e a expansão do comércio (ROLL, 1972).

A intensificação do poder do Estado, nessa época, determinou uma série de medidas, como a organização de monopólios. Sua presença regulamentou o comércio exterior e os transportes, visando aumentar o fluxo de dinheiro para dentro do país e, ao mesmo tempo, reduzir a sua saída (HUNT, 1981).

O Estado passa a ser forte e interventor, por meio do apoio aos comerciantes, sendo que estes viam nele uma forma de assegurar o atendimento exclusivo dos seus interesses, em detrimento dos interesses do indivíduo e da comunidade. Neste período é possível perceber a determinação da organização política pela influência marcante da organização econômica. O respeito dos governos pela autonomia econômica torna-se virtualmente uma ideologia, só intervindo quando solicitados (ROSENBERG; BIRDZELL, 1986). Mas, na fase que sucedeu ao mercantilismo, chamada capitalismo industrial, a intervenção do Estado passa a ser vista como prejudicial ao crescimento econômico, em comparação ao livre jogo do mercado.

É importante lembrar que no período mercantilista ocorre a formulação de duas utopias que, apesar de divergentes, têm em comum o otimismo em face do mundo vindouro. A utopia liberal considerava que a propriedade, a livre iniciativa e o livre jogo do mercado, sem intervenção do Estado, assegurariam o melhor mundo possível, o laissez-faire. E a utopia socialista em que o comunismo deveria necessariamente suceder ao capitalismo, por meio das realizações associacionistas e cooperativistas, das lutas populares e operárias, da formação e do amadurecimento das classes operárias (BEAUD, 1991).

Cada uma destas utopias angariou defensores e adeptos ao longo da história do Estado que, adaptando-se às mudanças do capitalismo, de mercantil à industrial, atualmente vem a sofrer uma nova mudança, relacionada ao fenômeno denominado de globalização. Corazza (1997) o aponta como a dinâmica macroeconômica que ocasionou a substituição das instituições do Estado de Bem- 
estar Social e do Estado Desenvolvimentista, por exigir flexibilização e desenvolvimento das finanças e o domínio da lógica financeira sobre as atividades produtivas. Os Estados que se resignam à globalização confiam que as forças de mercado criarão uma nova ordem e desenvolvimento.

É para estar aptos a participar deste fenômeno de desenvolvimento que os Estados precisam seguir certas orientações ou exigências, como abrir-se ao mercado mundial, adequar seus preços aos preços internacionais, dar prioridade à economia de exportação, às políticas monetárias e fiscais, que devem ser orientadas para a redução da inflação e da dívida pública e para a vigilância da balança de pagamentos. Os direitos de propriedade privada devem ser claros e invioláveis, o setor empresarial do Estado deve ser privatizado, a tomada de decisão privada deve ditar os padrões nacionais de especialização, mobilidade dos recursos, dos investimentos e dos lucros. A regulação estatal da economia deve ser mínima, o peso das políticas sociais no orçamento do Estado deve ser reduzido (SANTOS, 2002).

Na visão de Santos (2002), a responsabilidade do Estado passa a ser criar o quadro legal e dar condições de efetivo funcionamento às instituições jurídicas e judiciais que tornarão possível o fluir rotineiro das infinitas interações dos cidadãos, com os agentes econômicos e com o próprio Estado. Tendo esse cenário como pano de fundo, Pereira (1998a) justifica a necessidade de reforma do Estado, recapitulando que nas sociedades pré-capitalistas e pré-democráticas prevalecia a Administração Patrimonialista, incapaz de distinguir entre o patrimônio público e os bens privados de seus governantes.

A ascensão do capitalismo e da democracia fez emergir um novo tipo de condução do Estado, a Administração Pública Burocrática. Esta forma de administração pública determinou a separação definitiva dos bens públicos e dos bens privados. Sob a análise de Weber, a adoção do novo sistema demonstrou a superioridade da autoridade racional sobre o poder patrimonialista (PEREIRA, 1998a).

Parece haver consenso quanto a que a transição do sistema patrimonialista para a administração burocrática obteve resultados positivos. O estabelecimento de controle hierárquico e formalista nos procedimentos em todas as esferas do Estado teve reflexos diretos na percepção dos cidadãos que poderiam, de alguma forma, compreender e acompanhar as atividades realizadas na administração dos bens públicos. Uma estratégia que poderia evitar a corrupção e o nepotismo, porém, era lenta, cara e ineficiente. Segundo Pereira (1998b), era uma forma de administração que atendia às necessidades de um Estado pequeno, que não era a realidade encontrada nos Estados do século XX, onde haviam sido incorporadas pelo Estado as funções de educação, saúde, cultura, seguridade social, incentivo à ciência e 
tecnologia, investimentos em estrutura e proteção do meio ambiente, na busca do Estado de Bem-Estar Social. Esse contexto, conduzido pela administração burocrática facilitou algumas modalidades de apropriação de parte do patrimônio público por parte de empresários e da classe média (PEREIRA, 1998b).

AAdministração Pública Gerencial despontou na década de 1960 como resposta à crise do Estado, para enfrentar a crise fiscal, reduzir os custos e tornar sua administração mais eficiente. Como características principais podem ser citadas: a orientação para o cidadão e obtenção de resultados, a disposição de confiança limitada aos funcionários públicos e políticos, a descentralização do incentivo à criatividade e inovação e a utilização de contrato de gestão para controlar os gestores públicos (PEREIRA, 1998b).

Na visão de Pereira (1998b), um exemplo de aplicação da administração pública gerencial pode ser percebido na atuação do governo britânico dos anos 1980. A partir de então, em todo o mundo houve forte movimentação para a reforma do setor público, motivado pelo exemplo inglês. Grande parte dos governos tentou modernizar e agilizar a administração pública. Os governos foram pressionados a reduzir o tamanho do Estado, para alcançar mais rapidamente a eficiência, a eficácia e a redução de seus custos (KETTL, 1998).

O Gerencialismo, denominação adotada na nova forma de administração, pressupõe uma reestruturação do Estado, com aumento de produtividade, redução de custos e orientação para o serviço público. Sua origem está na adaptação da administração de organizações de negócios à realidade da administração pública, em que o cidadão passa a ser identificado como consumidor, que possui necessidades a serem atendidas. A idéia é descentralizar, delegar autoridade e definir claramente os setores em que o Estado opera, as competências e as modalidades de administração mais adequadas a cada setor (PEREIRA, 1998b).

No Brasil, a reforma do Estado determinou quatro setores, a saber:

. O núcleo estratégico, onde são definidas as leis e políticas públicas.

- As atividades exclusivas, onde é exercido o poder de legislar e tributar, incluindo a política, as forças armadas, os órgãos de fiscalização e de regulamentação e os órgãos responsáveis pelas transferências de recursos.

. Os serviços não-exclusivos, realizados ou subsidiados pelo Estado, por serem considerados de alta relevância para os direitos humanos ou envolverem economias externas, que não podem ser recompensados no mercado por meio da cobrança dos serviços. São considerados serviços não-exclusivos as universidades, os hospitais, os centros de pesquisa e os museus. 
- A produção de bens e serviços realizada pelo Estado por meio das empresas de economia mista que operam em setores de serviços públicos e/ou setores estratégicos (PEREIRA, 1998b).

Para a efetivação da reforma do Estado, a questão da propriedade é essencial. O ensino superior é classificado, na referida reforma, como um serviço nãoexclusivo; portanto não há necessidade de ser propriedade do Estado. A alternativa é a adoção do regime de propriedade pública não-estatal. "Pública, no sentido de que se deve dedicar ao interesse público, de que não visa ao lucro. Não-estatal, porque não faz parte do aparelho do Estado” (PEREIRA, 1998a, p. 34-35). A justificativa para a mudança segue nos seguintes termos:

Nos Estados Unidos, todas as universidades são organizações públicas nãoestatais. Podem ser consideradas “privadas” ou “controladas pelo Estado”, mas, a rigor, não visam ao lucro e também não empregam servidores públicos. São parcialmente financiadas ou subsidiadas pelo Estado - sua face "privada" é menor que a face “controlada pelo Estado” - mas são entidades independentes, controladas por juntas que representam a sociedade civil e em posição minoritária - pelo Estado. No Reino Unido, as universidades e os hospitais sempre estiveram sob o controle do Estado; agora já não é assim: hoje são “organizações quase não-governamentais” (“quangos”). Não foram privatizadas: passaram do controle do Estado para o controle público (PEREIRA, 1998a, p. 35).

A partir desta visão, é possível relacionar as dificuldades encontradas, nos últimos anos, pelas universidades públicas brasileiras com as intenções manifestadas no projeto de reforma do Estado. Aliada a este fator, a grande demanda por profissionais com maior qualificação, gerada pelo mercado de trabalho, também influencia a abertura de novas instituições de ensino superior no país. Além disso, algumas experiências estão demonstrando que o investimento em faculdades privadas, atualmente, é um ramo de negócio que pode proporcionar bons retornos.

\section{A Reforma da Educação Superior no Brasil}

A apresentação do documento final da nova LDB, sancionada em dezembro de 1996, gerou a manifestação de análises positivas e negativas de alguns autores da área de educação (CHAUÍ, 2001; DEMO, 1998; NISKIER, 1997; SAVIANI, 1997). Para este estudo serão enfocados os aspectos da lei que tratam especificamente do ensino superior, que possam contribuir para o alcance dos objetivos propostos neste artigo. 
O estudo dos textos que tratam da organização da educação nacional e da nova LDB possibilita a constatação de que a União pretende atuar, no caso do ensino superior, apenas como órgão controlador. A União incumbir-se-á de:

[...] baixar normas gerais sobre cursos de graduação e pós-graduação; assegurar processo nacional de avaliação das instituições de educação superior, com a cooperação dos sistemas que tiverem responsabilidade sobre este nível de ensino; autorizar, reconhecer, credenciar, supervisionar e avaliar, respectivamente, os cursos das instituições de educação superior e os estabelecimentos do seu sistema de ensino (NISKIER, 1997, p. 32).

Posições favoráveis ao direcionamento dado pela nova LDB, no que tange ao ensino superior, justificam-se com o levantamento de pontos negativos do sistema anterior que podem ser corrigidos com a nova lei. Para Niskier (1997) a crise na universidade brasileira não é um fato isolado, mas parte de uma crise maior, de natureza econômico-financeira que atinge toda a sociedade. Para o autor, só a partir da solução de alguns aspectos do quadro emergencial é que será possível dar maior atenção às dificuldades das escolas de ensino superior. Os problemas vão além dos salários baixos do funcionalismo: as universidades enfrentam dificuldades que vão desde a manutenção de laboratórios, leitos de hospitais universitários, salas de aula, até a impossibilidade de ampliação da estrutura para atender as necessidades imediatas geradas pelo andamento de suas atividades.

Niskier (1997) afirma que no último quarto de século, o sistema de ensino superior cresceu em número de instituições e número de alunos. Em sua opinião, porém, este dado não reflete existência de qualidade e competência. Existem altos e baixos do ensino superior que distanciam nossas universidades de uma regularidade. Há uma baixa freqüência aos cursos, baixa avaliação do aprendizado e baixa qualidade de ensino. Aliado a isso existe alto índice de desistência, alta evasão do magistério qualificado e baixa remuneração de professores e especialistas. Para o autor, a nova LDB é uma evolução, pois

O Decreto 2207, de 15 de abril de 1997, assinado pelo presidente Fernando Henrique Cardoso, trouxe uma série de inovações no sentido de reorganização do ensino superior brasileiro. Por exemplo, as instituições particulares de ensino superior poderão se constituir como entidades com fins lucrativos [grifo nosso], sujeitando-se às regras das sociedades mercantis. [...] alterou a classificação das entidades de ensino superior que passaram a se enquadrar nas seguintes categorias: universidades, centros universitários, faculdades integradas, institutos superiores ou escolas superiores (NISKIER, 1997, p. 1).

Em 1997 foram publicadas as portarias que dispõem sobre o credenciamento de centros universitários, faculdades integradas, faculdades, institutos superiores ou escolas superiores e também sobre a autorização para novos cursos em todos 
estes tipos de instituições. Estes instrumentos legais, devido ao seu conteúdo, podem ser interpretados, segundo Niskier (1997), como uma revolução qualitativa no ensino superior brasileiro.

A partir de então passou a ser exigida formação de mestrado e doutorado para o magistério superior, na busca de um salto de qualidade, evitando o amadorismo e a irresponsabilidade. Para Niskier (1997), até então haviam sido criadas muitas escolas superiores sem corpo docente no mínimo razoável. Com a nova LDB, o MEC busca pôr fim à indústria do currículo, que facilita a autorização de novos cursos superiores sem a ocorrência de aulas.

Saviani (1997) manifesta sua discordância com a posição de Niskier (1997), afirmando que a estrutura e o conteúdo do texto da nova LDB formam um documento em sintonia com a orientação política dominante naquele momento. O Ministério da Educação optou por adotar um texto inócuo e genérico, minimalista de acordo com Luiz Antonio Cunha (apud SAVIANI, 1997). Há preferência pelo trabalho de implementação de uma política global, não anunciada claramente na LDB, por meio de reformas pontuais, buscando evitar as pressões e resistências possíveis. Esta nova LDB se transformou em um mecanismo de viabilidade para aplicação de uma estratégia global (SAVIANI, 1997).

Saviani (1997) é um dos críticos da nova lei, por entender que, mais uma vez, perde-se a oportunidade de traçar as coordenadas e criar os mecanismos capazes de viabilizar a construção de um sistema nacional de educação aberto, abrangente e adequado às aspirações da sociedade brasileira. O Estado se propõe a formular políticas educacionais, transferindo sua responsabilidade para outras instâncias. Para o autor, o discurso reconhece a importância da educação, busca reduzir os investimentos e apela à iniciativa privada e organizações não-governamentais, deixando a questão da educação para a boa vontade pública. No caso do ensino superior, a política de expansão estimulou a criação de faculdades isoladas, invertendo-se a prescrição legal que tem preferência pela forma universitária (SAVIANI, 1997).

Demo (1998) também acredita que a parte mais decadente da nova LDB é a sua visão sobre educação superior. Dentre as diversas observações são relevantes os aspectos voltados para a linguagem arcaica que define as finalidades genéricas da educação superior. É percebida como positiva a proposta de avaliação de instituições de educação superior, vinculando a ela a autorização e o reconhecimento dos cursos, bem como o credenciamento das próprias instituições; porém o texto não vincula claramente a avaliação à intervenção e ao descredenciamento. Para o autor, a lei banaliza o ensino superior, quando permite considerar universidades entidades primárias, que não têm condições mínimas de reconstrução própria de conhecimento. 
Chauí (2001) aprofunda ainda mais a crítica à questão da reforma da educação, lembrando que ela é fruto da reforma do Estado e esta, do neoliberalismo. Neoliberalismo que a autora conceitua como a redução do político aos mecanismos diretos da economia, reduzir a economia à finança, identificar a finança com o jogo do mercado e considerá-lo o ponto final da história humana.

Chauí (2001) adverte que para melhor entender a LDB é preciso ler o texto do Banco Interamericano de Desenvolvimento - BID, depois o da Lei, na seqüência, os textos das reitorias e das faculdades, e perceber a homogeneidade de pensamento, de idéia. O BID tem como eixo o par custo-benefício. Na opinião de Chauí (2001), por se tratar de um banco, isto não é nenhum demérito. Contudo o MEC também o utiliza, como as reitorias e as faculdades. O BID deixa claro que as universidades brasileiras têm um custo muito alto e um benefício muito pequeno. Como é detectado “pequeno benefício” não é explicitado. Outro critério, a inoperância, está dividida em três aspectos: baixa qualidade de ensino e pesquisa, altíssimo índice de evasão com alto custo com pessoal (pouco aluno por professor), e o par recompensa-punição (não existência de um bom sistema de recompensa por produtividade e punição por improdutividade) (CHAUÍ, 2001).

Segundo Chauí (2001) o BID investirá nas universidades brasileiras que se reformarem. Em total harmonia com o BID, fala o MEC na LDB, em relação à autonomia de gerenciamento de recursos, racionalização de pessoal, avaliação por produtividade, flexibilização de currículos das áreas profissionais, técnicas e generalistas. Na opinião da autora, agravando o problema, as direções universitárias parecem pensar da mesma maneira que um banco.

Concordando com Chauí (2001), Ribeiro (2001) afirma que a LDB, influenciada pelo neoliberalismo, aumentou a dicotomia entre educação, cidadania e trabalho, mudando seu papel na sociedade. Com o ressurgimento de um liberalismo que deseja cada vez mais a ampliação dos mercados de capital, o poder público e estatal perderam o apoio da sociedade. Seus beneficiados, os alunos, são vistos agora como clientes. Segundo Ribeiro (2001) a privatização educacional foi celebrada como conquista da nova concepção de cidadania: agora é o cidadão que escolhe onde vai estudar

Nas legislações educacionais anteriores era o Estado brasileiro o responsável pela educação. Na escola neoliberal, os pais são chamados a decidir sobre tais questões. O privado funciona como árbitro do destino social das instituições educacionais. O neoliberalismo desse final de milênio desabrigou o público e prega uma identidade fundamentada na qualidade e na eficiência do mercado (RIBEIRO, 2001). 
A escola passa a ser vista por muitos educadores, como um fast-food. "Na educação neoliberal as instituições escolares devem funcionar como empresas produtoras de serviços educacionais” (RIBEIRO, 2001, p. 70), conquistando nichos que respondam pelas demandas de consumo por educação, demandas que aumentaram consideravelmente nos últimos cinco anos, na Região Sudoeste do Paraná.

\section{Metodologia}

A busca para a compreensão do fenômeno, aqui enfocado, envolveu a realização de uma pesquisa com caráter exploratório. Segundo Triviños (1987), os estudos exploratórios auxiliam o pesquisador a encontrar elementos necessários que permitam, em contato com determinada população, obter dados sobre os quais ainda não se tem informação. A pesquisa exploratória permite a visualização de um panorama inicial sobre determinada população.

Assim sendo, o trabalho foi concebido a partir da seguinte sistematização: pesquisa bibliográfica acerca dos temas Reforma do Estado e Reforma da Educação Superior, pois se partiu da premissa de que o entendimento da rápida expansão do ensino superior na região requer a compreensão do contexto dessas reformas; coleta de dados secundários por meio de pesquisa documental nas páginas institucionais da Internet, para a caracterização da Região Sudoeste do Paraná e a descrição do histórico do ensino superior ali existente até 1999, ano a partir do qual se iniciou seu acelerado processo de expansão; e coleta de dados primários por meio de aplicação de questionários aos coordenadores dos Cursos de Administração das instituições de ensino superior, presentes na região. Os questionários foram entregues nas secretarias dos cursos e posteriormente recolhidos pelas pesquisadoras.

No processo de análise dos dados, partiu-se das discussões encontradas na literatura acerca dos temas estudados, para tentar compreender o contexto do aumento do número de cursos superiores no Brasil, a partir das referidas reformas. A categorização foi feita de acordo com o instrumento de coleta de dados utilizado e com as implicações teóricas apresentadas. Os aspectos considerados importantes para a interpretação do fenômeno foram: o ano de instalação dos cursos; as notas no Exame Nacional de Cursos; a relação vagas por candidatos; o valor das mensalidades e a titulação dos docentes. Nesse sentido, buscou-se, nesses indicadores, evidências de que mudanças significativas ocorreram no ensino superior da região, institucionalizadas por transformações maiores, representadas aqui pela Reforma do Estado e Reforma do Ensino Superior. O resultado dessa análise será descrito a seguir. 


\section{O Ensino Superior na Região Sudoeste do Paraná: Antecedentes}

A Região Sudoeste do Paraná abrange, segundo a Associação dos Municípios do Sudoeste do Paraná - AMSOP - uma área de 17.102.750 km² que ocupa a margem esquerda do Rio Iguaçu e vai do município de Palmas até a fronteira com a Argentina e com o Oeste de Santa Catarina, dividida em 42 municípios com o total de 557.044 habitantes. Em grande parte os municípios são pequenos, com a população inferior 40.000 habitantes; apenas dois deles podem ser identificados como cidades-pólo, com população superior a 62.000 habitantes.

De acordo com dados do Instituto Brasileiro de Geografia e Estatística - IBGE: a) a maior parte da população da região é urbana; b) a maior renda é proveniente do setor de serviços, seguido por um equilíbrio entre a indústria e a agropecuária; c) o setor industrial é composto por empresas classificadas como micro e pequenas, com algumas exceções de médio e grande porte.

Quanto à educação, no ensino fundamental e médio, o predomínio é de escolas públicas, distribuídas nas áreas urbana e rural dos municípios. São encontradas algumas escolas da iniciativa privada, vistas como referência de ensino de qualidade nas cidades pólo. Nos municípios menores, em alguns casos não há nenhuma escola privada, devido ao número reduzido da população e sua condição socioeconômica.

Por um período de 30 anos, de 1969 até 1999, o ensino superior da Região Sudoeste do Paraná contou com três Instituições em funcionamento. Estas ofereciam um total de 25 cursos, com aproximadamente 1200 vagas em diversas áreas. Um breve histórico destas instituições pode ser assim descrito:

\section{a) A FACIPAL - Faculdades Integradas de Palmas}

A Faculdade de Filosofia, Ciências e Letras - FAFI, fundada em 1969, mantida e administrada pelo Centro Pastoral, Educacional e Assistencial Dom Carlos CPEA, obteve reconhecimento pelo Decreto Federal $n^{0} 72.452 / 1973$ e foi a primeira instituição de ensino superior da região. Oferecia os cursos de Filosofia, Pedagogia, História e Letras Francês. Em 1979, iniciaram suas atividades as Faculdades Reunidas de Administração, Ciências Contábeis e Ciências Econômicas de Palmas - FACEPAL, estabelecimento de Ensino Superior de Direito Público, mantido pela Prefeitura Municipal de Palmas e administrado por meio de convênio pelo CPEA, reconhecidas pela Portaria Ministerial nº 76/1983. 
Em 2000, o CPEA tornou-se também a mantenedora da FACEPAL e, em 2001, FAFI e FACEPAL foram transformadas em uma só Instituição, recebendo a atual denominação, FACIPAL, pela Portaria n ${ }^{0}$ 285/2001. Possui atualmente 18 cursos de graduação nas mais diversas áreas, 21 cursos de especialização e 2 mestrados. Integram seu corpo docente 174 professores, desde graduados até doutores.

\section{b) A UNIOESTE - Universidade Estadual do Oeste do Paraná}

Em 1975 ocorre o primeiro vestibular da Fundação Faculdade de Ciências Humanas de Francisco Beltrão - FACIBEL, com a co-participação do CPEA. Criada pela Lei n 477/1974, homologada pelo Prefeito Antônio de Paiva Cantelmo, oferecia vagas para os cursos de Estudos Sociais - licenciatura curta e, para o curso de Economia Doméstica - licenciatura e bacharelado, na cidade de Francisco Beltrão.

Em 1985 inicia o curso de Ciências Econômicas - bacharelado e, em 1986 o curso de Geografia - licenciatura plena e bacharelado. Em 1996, aconteceu o vestibular para Pedagogia - magistério das matérias pedagógicas do ensino de $2^{\circ}$ grau e magistério para a pré-escola.

A Lei n ${ }^{\circ} 12.235$ de 24 de junho de 1999 autorizou a incorporação do patrimônio e de todos os cursos de graduação da FACIBEL pela Universidade Estadual do Oeste do Paraná - UNIOESTE.

A UNIOESTE, em seu novo campus no município de Francisco Beltrão, passou a atuar dando seqüência aos cursos vindos da instituição anterior: Ciências Econômicas, Economia Doméstica, Geografia e Pedagogia. Estes são os cursos ainda hoje ofertados e para isso a Instituição conta atualmente com um corpo docente composto por 47 professores, de graduados a doutorandos.

\section{c) O CEFET/PR - Centro Federal de Educação Tecnológica do Paraná, Unidade de Pato Branco}

Em 1975, iniciou suas atividades a Faculdade de Ciências Contábeis e Administração de Pato Branco - FACICON, com os cursos de Administração e Ciências Contábeis, no município de Pato Branco. Em 1981 houve uma alteração na denominação, passando à Fundação de Ensino Superior de Pato Branco FUNESP. Em 1985 a FUNESP implantou os cursos de Letras e Matemática, em 1987 o curso de Processamento de Dados e em 1992 o curso de Agronomia (PASTRO, 1999). 
Em 1993 a FUNESP foi incorporada pelo Centro Federal de Educação Tecnológica do Paraná - CEFET-PR. Todos os cursos de graduação que estavam em funcionamento desde o início das atividades da Instituição passaram para o novo órgão mantenedor, que oferece atualmente 9 cursos de graduação e turmas de ensino médio, contando cerca de 200 professores.

Especificamente a graduação em Administração era ofertada por duas destas instituições, sendo uma pública, o CEFET-PR, e outra privada, a FACIPAL.

\section{A Situação Atual}

Assim como em outras regiões, na Região Sudoeste do Paraná o número de instituições de ensino superior conheceu aumento inesperado, tanto na percepção da comunidade acadêmica, quanto da sociedade, como demonstra a reportagem “A Explosão do Ensino Superior” apresentada por Pegoraro (2001). A partir do ano 1999, iniciou-se a implantação de novas instituições, totalizando doze instituições de ensino superior com 75 diferentes cursos de graduação, que disponibilizavam 4.745 novas vagas anualmente, até o final de 2001.

A seguir, será apresentado o perfil do ensino superior na Região Sudoeste do Paraná, por ocasião da coleta de dados para esta pesquisa, abordando alguns dados básicos sobre as instituições como um todo e trazendo informações mais específicas sobre os cursos de Administração, uma vez que o foco deste estudo está voltado para o ensino superior em Administração.

A realidade da Região Sudoeste do Paraná não é diferente do restante do país. Alguns anos após a expansão do número de instituições privadas nas regiões mais centrais, vários pequenos municípios dispõem hoje de instituições que oferecem cursos superiores em diversas áreas, tendo destaque o grande número de cursos de graduação em Administração.

A relação entre o número de instituições e o número de habitantes dos diversos municípios pode confirmar a afirmação feita por Saviani (1997), sobre a Reforma da Educação. No caso do ensino superior, a política de expansão estimulou a criação de faculdades isoladas ou novas instituições, invertendo-se a prescrição legal que tem preferência pela forma universitária.

As primeiras instituições da região instalaram-se nos municípios considerados pólos, com maior população ou entre os mais antigos da região, além da posição geográfica estratégica. Este fato poderia colaborar para o crescimento de algumas 
instituições, de faculdades para centros universitários, se as demandas possibilitassem. O Quadro 1 mostra que a instituição que mais oferece cursos é a FACIPAL, herdeira da primeira instituição criada na região, a FAFI, criada em 1969 na cidade de Palmas.

\section{Quadro 1: Localização das Instituições que Oferecem o Curso de Administração na Região, Ano de Instalação e Número de Cursos Oferecidos em 2002}

\begin{tabular}{|c|c|c|c|c|}
\hline Município & $\begin{array}{c}\mathrm{N}^{0} \text { de } \\
\text { habitantes }\end{array}$ & Instituição & $\begin{array}{c}\text { Ano de } \\
\text { Instalação }\end{array}$ & $\begin{array}{c}\text { Cursos em } \\
2002\end{array}$ \\
\hline Chopinzinho & 20.543 & PALAS ATENA & 2001 & 04 \\
\hline Clevelândia & 18.296 & FESC & 2001 & 02 \\
\hline \multirow[t]{2}{*}{ Dois Vizinhos } & \multirow[t]{2}{*}{31.984} & VIZIVALI & 1999 & 04 \\
\hline & & UNISEP & 2001 & 06 \\
\hline \multirow{3}{*}{ Francisco Beltrão } & \multirow{3}{*}{67.132} & UNIPAR & 2001 & 08 \\
\hline & & CESUL & 1997 & 01 \\
\hline & & UNIOESTE & 1999 & 04 \\
\hline Palmas & 34.783 & FACIPAL & 2001 & 20 \\
\hline \multirow{3}{*}{ Pato Branco } & \multirow{3}{*}{62.167} & CEFET & 1993 & 09 \\
\hline & & MATER DEI & 2000 & 05 \\
\hline & & FADEP & 2000 & 10 \\
\hline Realeza & 16.008 & CESREAL & 2001 & 02 \\
\hline Total & & 12 & & 75 \\
\hline
\end{tabular}

Fonte: adaptado de Pegoraro, 2001.

Realizando uma comparação entre o total de instituições e cursos ofertados, percebe-se um acréscimo de 300\% no número de escolas superiores e aproximadamente $120 \%$ no número de cursos oferecidos. É um aumento rápido e considerável, tanto de cursos quanto de instituições para uma região que conta com uma população de 557.044 habitantes e que, segundo os últimos censos do IBGE, vem sofrendo um decréscimo, causado pelo controle informal da natalidade e pelo êxodo para regiões com maior oferta de trabalho.

Até 2004 todos os cursos de Administração da Região terão participado de seu primeiro provão. Esta é uma preocupação constantemente manifestada pela direção e coordenações das diferentes instituições por dois aspectos: a importância do conceito a ser obtido para que os cursos sejam reconhecidos pelo MEC e possam permanecer no mercado; e a relevância do conceito para decisão do cliente sobre onde estudar. Ribeiro (2001) interpreta esse tipo de preocupação, quando afirma que a privatização da educação pode ser interpretada como mudança de valores e os alunos passam a ser vistos como clientes, que escolhem onde vão 
estudar. Essa escolha será altamente influenciada pela qualidade e eficiência no mercado. Os dados do Quadro 2 mostram que apenas duas das pioneiras já participaram do Exame Nacional de Cursos e apesar de terem conseguido o conceito B em 2000, não apresentaram o mesmo desempenho nos anos seguintes.

\section{Quadro 2: Conceito do Exame Nacional de Cursos para os Cursos de Administração}

\begin{tabular}{|l|c|c|c|}
\hline \multicolumn{1}{|c|}{ Instituição } & $\mathbf{2 0 0 0}$ & $\mathbf{2 0 0 1}$ & $\mathbf{2 0 0 2}$ \\
\hline \hline FACIPAL & $\mathrm{B}$ & $\mathrm{C}$ & $\mathrm{C}$ \\
\hline CEFET & $\mathrm{B}$ & $\mathrm{C}$ & $\mathrm{C}$ \\
\hline VIZIVALI & $*$ & $*$ & $*$ \\
\hline FADEP & $*$ & $*$ & $*$ \\
\hline MATER DEI & $*$ & $*$ & $*$ \\
\hline UNIPAR & $*$ & $*$ & $*$ \\
\hline CESREAL & $*$ & $*$ & $*$ \\
\hline UNISEP & $*$ & $*$ & $*$ \\
\hline FESC & $*$ & $*$ & $*$ \\
\hline PALAS ATENA & $*$ & $*$ & $*$ \\
\hline
\end{tabular}

* Instituições que ainda não participaram do Exame Nacional de Cursos.

O Quadro 3 mostra uma variação muito grande no número de candidatos. A CESREAL, por exemplo, que no vestibular de 2001 tinha 890 candidatos para 200 vagas, no ano seguinte teve apenas 490 candidatos para as mesmas 200 vagas. Ou seja, uma queda de $45 \%$. Outro dado que chama a atenção é que o número de candidatos por vaga gira em torno de 1 a 2,5. A exceção é o CEFET, que no vestibular de 2002 tinha quase 14 candidatos por cada vaga para o curso de Administração. O CEFET é uma das instituições pioneiras da região e a única que não cobra mensalidades, pois é uma instituição pública.

\section{Quadro 3: Número de Vagas Oferecidas versus Candidatos para os Cursos de Administração}

\begin{tabular}{||l||c|c||c|c||c|c||}
\hline \multicolumn{1}{|c||}{ Instituição } & \multicolumn{2}{c||}{$\mathbf{2 0 0 0}$} & \multicolumn{2}{c||}{$\mathbf{2 0 0 1}$} & \multicolumn{2}{c|}{ 2002 } \\
\hline & Vagas & Candidatos & Vagas & Candidatos & Vagas & Candidatos \\
\hline FACIPAL & 150 & 228 & 150 & 220 & 150 & 190 \\
\hline CEFET & 40 & 480 & 40 & 440 & 40 & 556 \\
\hline VIZIVALI & 80 & 120 & 80 & 120 & 80 & 144 \\
\hline FADEP & 250 & 274 & 200 & 223 & 200 & 307 \\
\hline MATER DEI & 200 & 380 & 120 & 280 & 60 & 145 \\
\hline UNIPAR & $*$ & $*$ & 160 & 140 & 80 & 100 \\
\hline CESREAL & $*$ & $*$ & 200 & 890 & 200 & 490 \\
\hline UNISEP & $*$ & $*$ & 100 & 111 & 50 & 59 \\
\hline FESC & $*$ & $*$ & 60 & 120 & 60 & 125 \\
\hline PALAS ATENA & $*$ & $*$ & NI & NI & NI & NI \\
\hline \hline TOTAL & $\mathbf{5 7 0}$ & $\mathbf{1 1 3 4}$ & $\mathbf{1 1 1 0}$ & $\mathbf{2 5 4 4}$ & $\mathbf{9 2 0}$ & $\mathbf{2 1 1 6}$ \\
\hline
\end{tabular}

* Instituições que realizaram concurso vestibular somente a partir de 2001. $\mathrm{NI}$ - não informado. 
O predomínio do número de instituições privadas, agora com maior proximidade e acessibilidade para os acadêmicos, gera concorrência entre elas, e o valor das mensalidades cobradas pelas instituições pode ser um fator importante para decisão dos clientes. A UNIPAR, por exemplo, que cobra a mensalidade mais alta, no vestibular de 2002 teve apenas 100 candidatos para as 80 vagas do curso de Administração (ver Quadro 3). A análise desse quadro permite citar Ribeiro (2001), quando enfatiza que as instituições escolares passam a funcionar como empresas produtoras de serviços educacionais em busca de nichos que tenham demanda de consumo por educação. Essa parece ser a realidade encontrada atualmente na Região Sudoeste do Paraná.

\section{Quadro 4: Valor das Mensalidades para os Cursos de Administração (ano 2002)}

\begin{tabular}{|l|r|}
\hline \multicolumn{1}{|c||}{ Instituição } & \multicolumn{1}{c|}{ RS } \\
\hline \hline FACIPAL & 230,00 \\
\hline CEFET & 0,00 \\
\hline VIZIVALI & 214,00 \\
\hline FADEP & 270,00 \\
\hline MATER DEI & 307,00 \\
\hline UNIPAR & 327,00 \\
\hline CESREAL & 280,00 \\
\hline UNISEP & 242,00 \\
\hline FESC & 180,00 \\
\hline PALAS ATENA & 288,00 \\
\hline
\end{tabular}

Uma grande parcela dos professores que trabalha nos cursos de graduação em Administração na Região é formada por mestres ou especialistas. Ainda são poucos os doutores, mas em compensação, também é muito reduzido o número de graduados. A FACIPAL, pioneira, é a que possui o maior número de mestres (16), seguida pela PALAS ATENA (13), MATER DEI (12) e a FADEP (11). Estes dados demonstram a preocupação das instituições privadas com a qualificação docente para atendimento deste quesito, avaliado pelo Exame Nacional de Cursos. 


\section{Quadro 5: Titulação do Corpo Docente em 2002 nos Cursos de Administração}

\begin{tabular}{|l|c||c|c|c|c|}
\hline \multicolumn{1}{|c|}{ Instituição } & Graduados & Especialistas & Mestres & Doutores & Total \\
\hline \hline FACIPAL & 01 & 05 & 16 & 01 & 23 \\
\hline CEFET & 00 & 10 & 08 & 00 & 18 \\
\hline VIZIVALI & 01 & 10 & 06 & 01 & 18 \\
\hline FADEP & 00 & 16 & 11 & 00 & 27 \\
\hline MATER DEI & 01 & 11 & 12 & 01 & 25 \\
\hline UNIPAR & 01 & 08 & 04 & 02 & 15 \\
\hline CESREAL & 01 & 06 & 04 & 00 & 11 \\
\hline UNISEP & 00 & 03 & 04 & 00 & 07 \\
\hline FESC & 00 & 03 & 09 & 00 & 12 \\
\hline PALAS ATENA & 00 & 05 & 13 & 00 & 18 \\
\hline
\end{tabular}

\section{Considerações Finais}

A partir da análise dos textos utilizados para organização deste trabalho, é possível perceber que a expansão do ensino superior em Administração na Região Sudoeste do Paraná não é um caso isolado. O fenômeno está ligado a uma situação decorrente de eventos maiores e anteriores, como a Reforma do Estado e da Educação. Estas reformas aprofundaram ainda mais as dificuldades encontradas, nos últimos anos, pelas universidades públicas, criando um novo nicho de inserção dos centros universitários e faculdades privadas dedicadas primordialmente ao ensino, que colaboraram para a passagem da interpretação do aluno como sujeito em processo de formação para o aluno cliente e da instituição de ensino superior como entidade produtora de serviços educacionais.

Outro aspecto a ser considerado na referida expansão é a oferta massiva de cursos de graduação que não exigem grandes investimentos em laboratórios, materiais e até mesmo grandes esforços para a composição do corpo docente. Possivelmente, esta seja uma justificativa para a presença da graduação em Administração na maior parte dessas novas instituições.

Uma análise global dos dados coletados, sob a luz da fundamentação teórica em que se baseia, permite afirmar que um conjunto de dados como localização da instituição, conceito obtido pelos cursos, titulação do corpo docente e valor das mensalidades praticadas, poderão ser fatores que influenciarão na decisão do acadêmico cliente sobre onde estudar. Sem dúvida alguma, o Estado brasileiro, por meio da Reforma da Educação Superior, permitiu que um número muito maior de pessoas tivesse acesso ao ensino superior. É necessário refletir, portanto, se em termos qualitativos, houve ganhos no sistema educacional como 
um todo ou um nivelamento por baixo, por meio da efetivação da lei de mercado na educação superior.

Artigo recebido em 31.10.2003. Aprovado em 19.10.2004.

\section{ReferênCias Bibliográficas}

BEAUD, $M$.

História do Capitalismo. De 1500 até nossos dias. 3. ed. São Paulo: Brasiliense, 1991. p. 122-185.

CHAUÍ, M.

As humanidades contra o humanismo. In: SANTOS, G.A. (Org.). Universidade, formação, cidadania. 1. ed. São Paulo: Cortez, 2001. p. 15-32.

CORAZZA, G.

Globalização: realidade e utopia. Análise Econômica. Porto Alegre: Faculdade de Ciências Econômicas, UFRGS, n. 27, ano 15, p.16-27, mar. 1997.

COVRE, M. L. M.

A formação e a ideologia do administrador de empresas. 3 ed. São Paulo, Cortez, 1991. p. 59-86.

DEMO, P.

A nova LDB: ranços e avanços. 6. ed. Campinas: Papirus, 1998. p. 67-89.

HUNT, E. K.

História do pensamento econômico uma perspectiva crítica. 7. ed. Rio de Janeiro: Campus, 1981, p. 41-43.
KETTL, D.

A revolução global: reforma da administração do setor público. In: PEREIRA, L. C. B.; SPINK, P. (Orgs.). Reforma do Estado e administração pública gerencial. 1. ed. Rio de Janeiro: Fundação Getúlio Vargas, 1998. p. 75121.

\section{LOPES, P.}

Reflexões sobre as bases da formação do administrador profissional no ensino de graduação. In: ENCONTRO ANUAL DA ANPAD, 26, 2002, Salvador, Anais... Salvador: ANPAD 2002, p. 03-04.

NICOLINI, A.

Qual será o futuro das fábricas de administradores? In: ENCONTRO ANUAL DA ANPAD, 25, 2001. Campinas, Anais... Campinas: ANPAD, 2001, p. 2-3.

NISKIER, A.

LDB - a nova lei da educação. 5. ed. Rio de Janeiro: Consultor, 1997, p. 1-35. 
PASTRO, I. I.

Reações dos professores à incorporação da Faculdade de Ciências e Humanidades de Pato Branco pelo Centro Federal de Educação Tecnológica do Paraná. 1999. 136 f. Dissertação (Mestrado em Administração) - Universidade Federal de Santa Catarina, Florianópolis.

\section{PEGORARO, I. A.}

Uma avalanche de faculdades muda mentalidade e perspectivas do sudoeste. Gente do Sul. Francisco Beltrão: Editora Jornal de Beltrão, n. 82, ano VII, p. 23-28, mar. 2001.

PEREIRA, L. C. B.

Gestão do setor público: estratégia e estrutura para um novo Estado. In: PEREIRA, L. C. B.; SPINK, P. (Orgs.). Reforma do Estado e administração pública gerencial. 1. ed. Rio de Janeiro: Fundação Getúlio Vargas, 1998a, p. 21-38.

Da administração pública burocrática à gerencial. In: Reforma do Estado e administração pública gerencial. 1. ed. Rio de Janeiro: Fundação Getúlio Vargas, 1998b, p. 237-270.
RIBEIRO, A. I. M.

Formação educacional: instrumento de acesso à cidadania? In: SANTOS, G. A . (Org.). Universidade, formação, cidadania. 1. ed. São Paulo: Cortez, 2001. p. 63-73.

ROLL,E.

História das doutrinas econômicas. 4. ed. São Paulo: Companhia Editora Nacional, 1972, p. 38-70.

ROSENBERG, N.; BIRDZELL JR, L. E.

A História da Riqueza do Ocidente. A transformação econômica no mundo industrial. Rio de Janeiro: Record, 1986. p. 152-191.

SANTOS, B. S. de.

Os processos da globalização. In: SANTOS, B. S. de(Org.). A globalização em Ciências Sociais. 2. ed. São Paulo: Cortez, 2002. p. 25-94.

SAVIANI, D.

A nova lei da educação-LDB trajetória, limites e perspectivas. 1. ed. Campinas: Autores Associados, 1997. p. 199-220.

TRIVIÑOS, A. N.

Introdução à pesquisa em ciências sociais: a pesquisa qualitativa em educação. 1. ed. São Paulo: Atlas, 1987. p. 109-110. 